\title{
Ameliorative Effects of Sesame Seed Oil Against Penconazole-Induced Testicular Toxicity and Endocrine Disruption in Male Rats
}

\author{
Ibrahim H Borai', Azza A Atef ${ }^{1}$, Afaf A El-Kashoury'2, Rania A Mohamed ${ }^{2}$ and Mahmoud M Said*1 \\ ${ }^{1}$ Biochemistry Department, Faculty of Science, Ain Shams University, Egypt \\ ${ }^{2}$ Central Agricultural Pesticides Laboratory, Agricultural Research Center, Egypt \\ *Corresponding author: Mahmoud M Said, Biochemistry Department, Faculty of Science, Ain Shams University, Egypt
}

\section{ARTICLE INFO}

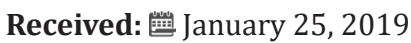

Published: 豐 February 04, 2019

Citation: Ibrahim H B, Azza A A, Afaf A E, Rania A M, Mahmoud M S. Ameliorative Effects of Sesame Seed Oil Against Penconazole-Induced Testicular Toxicity and Endocrine Disruption in Male Rats. Biomed J Sci \& Tech Res 14(1)-2019. BJSTR. MS.ID.002486.

Keywords: Penconazole; Reproductive Hormones; Sesame Seed Oil; Thyroid Hormones

\begin{abstract}
The current study investigated the protective effect of sesame seed oil (SSO) against testicular damage and endocrine disruption induced by the oral intoxication with penconazole (PENZ), a commonly used systemic triazole fungicide, in adult male Wistar rats. Subchronic oral exposure to two different doses of PENZ significantly reduced fertility indices, serum luteinizing hormone, follicle stimulating hormone, triiodothyronine and thyroxine levels, and by contrast a significant increase was recorded in serum estradiol and testosterone levels. Furthermore, PENZ significantly depleted testicular vitamins (A, C and E) level. On the other hand, administration of SSO prior to PENZ intoxication ameliorated most of the fertility indices and minimized PENZ-induced adverse effects on serum sexual, reproductive and thyroid hormones, compared to PENZ-treated animals. Histological data confirmed the biochemical findings. In conclusion, supplementation of SSO might be beneficial against the endocrine-disrupting potential and testicular toxicity induced by PENZ in adult male rats.
\end{abstract}

\section{Introduction}

Penconazole (PENZ), a fungicide that belongs to the triazole class, is commonly used in agriculture, horticulture and forestry industries for the control of powdery mildew [1]. It stops fungal growth by inhibiting lanosterol-14囚-demethylase (CYP51), which is required for ergosterol biosynthesis [2]. As a result of its in-depth utilization as an agrochemical, PENZ residues remain on treated crops, which may affect the environmental safety and human health $[3,4]$. Being refractory to degradation because of its long mean halflife value (117 days), PENZ is susceptible to accumulate in soils [5]. Sesame seed oil (SSO), derived from the seeds of Sesamum indicum L., is an important edible oil rich in fatty acids, including linoleic (39 to $59 \%$ ), oleic (35\% to $54 \%$ ), palmitic acid $(10 \%)$ and stearic acid (5\%), tocopherols, phytosterols and lignans, such as sesamin, sesaminol, sesamolin, and a small amount of sesamol, minerals including, iron, calcium, magnesium, zinc and copper, as well as $[6,7]$. The major lignan of sesame seed is sesamin that possesses a myriad of beneficial effects on human health [8-14].

Following exposure to agricultural pesticides, several studies demonstrated a reduction in sperm count and semen quality, considering the testis as a sensitive indicator of male reproductive toxicity $[15,16]$. Exposure to PENZ had been previously reported to cause structural and functional testicular toxicity in male rats [1]. Therefore, the current study was undertaken to verify PENZinduced toxic effects on rat testes and endocrine disrupting potential and the probable protective effect of SSO supplementation. 


\section{Materials and Methods}

\section{Animals}

Adult male Wistar rats were obtained from the breeding unit of the Egyptian Stock Holding Company for Biological Products, Vaccines, Sera and Drugs (Cairo, Egypt). The animals were housed in plastic cages (5/cage) with a free access to commercial pelleted diet and tap water for one week before the start of the experiment as an acclimatization period. All animal procedures were performed under protocols approved by the Local Institutional Animal Ethics Committee of the Agricultural Research Center in accordance with the Guide for the Care and Use of Laboratory Animals (17).

\section{Chemicals}

Penconazole [1-(2,4-dichloro- $\rrbracket-p r o p y l p h e n e t h y l)-1 H-1,2,4$ triazole; known commercially as Topas $₫ 100 \mathrm{EC}]$ was obtained from Syngenta Company (Egypt) as a 10\% emulsifiable concentrate (EC) formulation. Sesame seed oil (SSO) extracted from the seeds of Sesamum indicum L., was purchased from a local market (Haraz, Egypt).

\section{Determination of PENZ Median Lethal Dose (LD50)}

The median lethal dose (LD50) of PENZ was determined in adult male Wistar rats according to the OECD guideline for the testing of chemicals [18].

\section{Experimental Protocol}

In total, 60 adult male Wistar rats were equally allocated into six groups as follows: Normal control group: Rats were supplemented with the basal diet and left without any treatment. Negative control group (SSO): Rats were supplemented with SSO using an intragastric tube at a dose of $1 \mathrm{ml} / \mathrm{kg}$ bw (5 days/week) for three consecutive months [19]. Positive control group I (LD PENZ): Rats were intoxicated with $30 \mathrm{mg} / \mathrm{kg}$ bw PENZ (1/20 of the LD50 of PENZ) using an intragastric tube five days per week for three consecutive months. Positive control group II (HD PENZ): Rats were intoxicated with $60 \mathrm{mg} / \mathrm{kg}$ bw PENZ (1/10 of the LD50 of PENZ) using an intragastric tube five days per week for three consecutive months. Preventive group I (SSO+LD PENZ): Rats were orally administered with SSO $(1 \mathrm{ml} / \mathrm{kg} \mathrm{bw}) 2 \mathrm{~h}$ prior to the oral intoxication with PENZ (30 mg/kg bw) 5 days per week for three consecutive months. Preventive group II (SSO+HD PENZ): Rats were orally administered with SSO $(1 \mathrm{ml} / \mathrm{kg} \mathrm{bw}) 2 \mathrm{~h}$ prior to the oral intoxication with PENZ (60 mg/kg bw) 5 days per week for three consecutive months.

\section{Blood Collection and Tissue Sampling}

At the end of the experimental period (90 days), animals were weighed, then blood samples were collected from the abdominal aorta under light ether anesthesia. A volume of $1 \mathrm{ml}$ blood was dispensed into a heparinized tube that was centrifuged at $200 \bigotimes \mathrm{g}$ for $5 \mathrm{~min}$ and the separated plasma was aliquoted and stored at $-40^{\circ} \mathrm{C}$. The remainder of blood was collected in a plain centrifuge tube and left to stand for $30 \mathrm{~min}$ at room temperature to clot.
The blood was centrifuged at $500 \bigotimes \mathrm{g}$ for $15 \mathrm{~min}$ and serum was separated, aliquoted and stored at $-40^{\circ} \mathrm{C}$. At autopsy, the epididymis was immediately removed for the evaluation of fertility indices. The right testis was immediately frozen in liquid nitrogen and kept at $-40^{\circ} \mathrm{C}$ until homogenization, whereas the left one was fixed in $10 \%$ phosphate-buffered formalin for histological examination.

\section{Preparation of Testicular Tissue Homogenate}

A 10\% testicular homogenate was prepared in ice cold 1.17\% potassium chloride using a chilled glass-Teflon Potter-Elvehjem tissue Homogenizer. An aliquot of the whole testicular tissue homogenate was used for the estimation of vitamin $\mathrm{C}$ concentration by the method of Henry et al. [20].

\section{Extraction of Vitamins A and E From Testicular Tissues}

Extraction of vitamins $\mathrm{A}$ and $\mathrm{E}$ from testicular tissues was done according to the method of Hinds et al. [21]. Testicular vitamin A and E concentrations were evaluated according to the colorimetric methods of Pett \& Lepage and Martinek [22,23], respectively.

\section{Fertility Indices}

A $10 \%(\mathrm{w} / \mathrm{v})$ homogenate was obtained by mincing the cauda epididymis of rats in isotonic saline at 37 for the evaluation of semen parameters, including sperm concentration and morphology [24] sperm motility [25] and sperm viability [26].

\section{Biochemical Assays}

Serum total testosterone (T) and estradiol (E2) levels were determined using RIA kits (Diagnostic Products Corporation, USA), while serum luteinizing hormone ( $\mathrm{LH})$ and follicle stimulating hormone (FSH) levels were analyzed using rat ELISA kits (Kamiya Biomedical Company, USA). Serum triiodothyronine (T3) and thyroxine (T4) levels were assayed using rat ELISA kits purchased from USCN and Cusabio Companies (USA), respectively.

\section{Histological Examination}

Testes fixed in formalin were embedded in paraffin and $4 \mu \mathrm{m}$ thick sections were processed by a microtome. Tissue slides were stained with haematoxylin and eosin (H\&E) and examined using a light microscope.

\section{Statistical Analysis}

The statistical difference between means was computed using one-way analysis of variance (ANOVA) followed by the posthoc Least Significant Difference (LSD) test for multiple comparisons at $\mathrm{p}<0.05$ level of significance. SPSS statistical software 22.0 for Windows (SPSS, Inc., Chicago, IL, USA) was used for all analyses.

\section{Results}

\section{Determination of the Acute PENZ Toxicity in Rats}

Four different ascending concentrations of PENZ (494.21, $593.05,711.66$ and $853.99 \mathrm{mg} / \mathrm{kg} \mathrm{bw}$ ) at a constant factor (1.2) were used. Twenty adult male Wistar rats were weighed and divided into four groups of five rats per group. Each rat was given 
orally the same dose of PENZ according to its weight. Toxicity signs of PENZ included paralysis, sedation, congestion in eyes and rough hair. The calculated oral median lethal dose (LD50) of PENZ, according to Weil [27], was $620.71 \mathrm{mg} / \mathrm{kg}$ bw.

\section{The Percentage Survival of Rats at the End of the Experiment}

No mortalities were recorded in normal control and SSO-administered rats, whereas PENZ treatment of low and high doses caused 20 and $40 \%$ deaths, respectively, and by contrast, administration of SSO prior to PENZ intoxication reduced the death percentage to only $10 \%$ in both SSO-supplemented groups at the end of the treatment period.

\section{Effect of Treatment with SSO and/or PENZ Intoxication on Body Weight as well as Relative Testis and Epididymis Weights}

Administration of SSO and/or PENZ caused non-significant changes in total body weight, as well as absolute and relative testis weights, whereas a significant reduction in absolute and relative epididymis weights (27.45 \& 25\%, respectively) was recorded in SSO-supplemented animals, compared to the normal control group. A similar significant change in absolute and relative epididymis weight was recorded following intoxication of male rats with the low PENZ dose (25.49 \& 30\%, respectively), compared to the nor- mal control group. Supplementation of SSO prior to PENZ intoxication reduced absolute and relative epididymis weights 37.25 , $35,31.37$ and $30 \%$, respectively), compared to the normal control group. Intergroup comparison between SSO-administered PENZ-intoxicated rats and PENZ-treated rats per se revealed a significant reduction in absolute epididymis weight (15.79 \& 27.08\%, respectively) (Table 1 ).

\section{Effect of Treatment with SSO and/or PENZ on Fertility Indices in Male Rats}

Treatment of male rats with low and high doses of PENZ resulted in the deterioration of fertility markers, as evidenced by the significant reduction in sperm count, motility as well as viability (35.80, 36.59, 29.76 and 33.33, 25.61, 13.10\%, respectively), accompanied by a significant increase in the sperm abnormal forms ( 241.76 and $191.67 \%$ ), respectively, compared to the normal control group. Administration of SSO before intoxication with the low and high doses of PENZ resulted in a significant decrease in sperm count, motility and viability, accompanied by a significant increase in abnormal forms (with low dose by 17.28, 14.63, 9.25, 125\% and high dose by $8.64,9.76,5.95,108.33 \%$ ) respectively, compared to the normal control group. Intergroup comparison between PENZ and protective groups showed that all the fertility-related parameters were ameliorated with SSO supplementation (Table 2).

Table 1: Effect of treatment with sesame seed oil (SSO) and/or penconazole (PENZ) on body weight, relative and absolute testis and epididymis weights in male rats.

\begin{tabular}{|c|c|c|c|c|c|}
\hline \multirow{3}{*}{ Groups } & \multirow{3}{*}{ Body weight (g) } & \multicolumn{2}{|c|}{ Testes } & \multicolumn{2}{|c|}{ Epididymis } \\
\hline & & Absolute & Relative & Absolute & Relative \\
\hline & & (g) & (\%) & (g) & (\%) \\
\hline \multicolumn{6}{|c|}{ Normal Control } \\
\hline Mean $\pm S D$ & $258.89 \pm 42.78$ & $2.88 \pm 0.32$ & $1.13 \pm 0.14$ & $0.51 \pm 0.09$ & $0.20 \pm 0.03$ \\
\hline \multicolumn{6}{|c|}{ Negative Control (SSO) } \\
\hline Mean \pm SD & $261.25 \pm 37.11$ & $2.74 \pm 0.32$ & $1.07 \pm 0.20$ & $0.37 \pm 0.05^{\mathrm{ad}}$ & $0.15 \pm 0.04^{\mathrm{a}}$ \\
\hline${ }^{*}$ Change $\%$ & 0.91 & -4.86 & -5.31 & -27.45 & -25 \\
\hline \multicolumn{6}{|c|}{ Positive Control I (LD PENZ) } \\
\hline Mean \pm SD & $264.50 \pm 24.32$ & $2.68 \pm 0.32$ & $1.02 \pm 0.15$ & $0.38 \pm 0.06^{\text {ade }}$ & $0.14 \pm 0.02^{\text {ad }}$ \\
\hline$*$ Change $\%$ & 2.17 & -6.94 & -9.73 & -25.49 & -30 \\
\hline \multicolumn{6}{|c|}{ Positive Control II (HD PENZ) } \\
\hline Mean \pm SD & $276.67 \pm 27.51$ & $2.70 \pm 0.30$ & $0.98 \pm 0.14$ & $0.48 \pm 0.07^{\text {bcef }}$ & $0.18 \pm 0.03^{\text {ce }}$ \\
\hline${ }^{*}$ Change $\%$ & 6.87 & -6.25 & -13.27 & -5.88 & -10 \\
\hline \multicolumn{6}{|c|}{ Preventive I (SSO+LD PENZ) } \\
\hline Mean \pm SD & $250.00 \pm 40.08$ & $2.41 \pm 0.42$ & $0.98 \pm 0.21$ & $0.32 \pm 0.06^{\text {acd }}$ & $0.13 \pm 0.03^{\text {ad }}$ \\
\hline${ }^{*}$ Change $\%$ & -3.43 & -16.32 & -13.27 & -37.25 & -35 \\
\hline${ }^{* *}$ Change $\%$ & -5.48 & -10.07 & -3.92 & -15.79 & -7.14 \\
\hline
\end{tabular}




\begin{tabular}{|c|c|c|c|c|c|}
\hline Preventive II (SSO+HD PENZ) & & & & \\
Mean \pm SD & $241.11 \pm 40.14$ & $2.62 \pm 0.60$ & $1.07 \pm 0.22$ & $0.35 \pm 0.08^{\text {ad }}$ & $0.14 \pm 0.02^{\mathrm{a}}$ \\
$*$ Change\% & -6.87 & -9.03 & -5.31 & -31.37 \\
${ }^{* * *}$ Change\% & -12.85 & -2.96 & 9.18 & -27.08 & -22.22 \\
\hline F-ratio & NS & NS & NS & 10.39 \\
\hline
\end{tabular}

Note: Results are mean \pm standard deviation (SD). The F-ratio is significant at $\mathrm{p}<0.05$. The letters $\mathrm{a}, \mathrm{b}, \mathrm{c}, \mathrm{d}, \mathrm{e}$, and $\mathrm{f}$ denote significant change versus the normal control group, SSO, LD PENZ, HD PENZ, SSO+LD PENZ, and SSO+HD PENZ groups, respectively. * **, *** percentage change versus normal control, LD PENZ and HD PENZ groups, respectively.

Table 2: Effect of treatment with sesame seed oil (SSO) and/or penconazole (PENZ) on fertility indices in male rats.

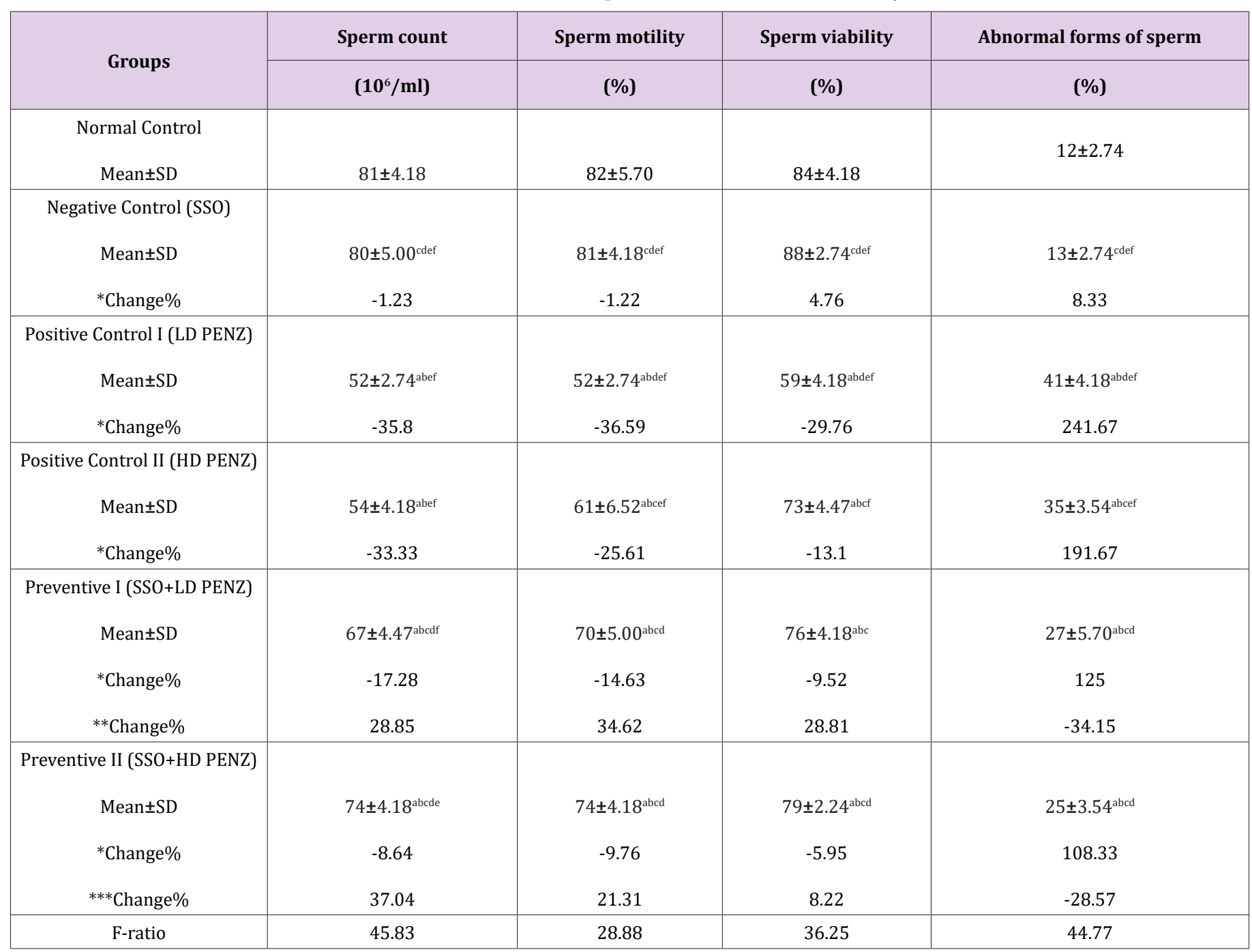

Note: Results are mean \pm standard deviation (SD). The F-ratio is significant at $\mathrm{p}<0.05$. The letters $\mathrm{a}, \mathrm{b}, \mathrm{c}, \mathrm{d}, \mathrm{e}$, and $\mathrm{f}$ denote significant change versus the normal control group, SSO, LD PENZ, HD PENZ, SSO+LD PENZ, and SSO+HD PENZ groups, respectively. * **, *** percentage change versus normal control, LD PENZ and HD PENZ groups, respectively.

Effect of treatment with SSO and/or PENZ on Serum Testosterone (T), Estradiol (E2), Follicle Stimulating Hormone (FSH) and Luteinizing Hormone (LH) levels

The intoxication of adult male rats with low and high doses of PENZ resulted in a significant increase in serum estradiol levels (50.73 and $33.60 \%$, respectively), along with a significant reduction in serum FSH and LH levels $(20.29,17.50 \& 38.21,33.16 \%$, respec- tively), whereas serum testosterone level recorded a significant increase $(96.88 \%)$ in the high dose PENZ-treated rats, compared to the normal control group. On the other hand, administration of SSO before the high dose PENZ intoxication normalized serum testosterone level. Intergroup comparison showed that administration of SSO before the low dose PENZ intoxication resulted in a slight significant reduction in serum E2 level (7.82\%), accompanied by a 
significant increase in serum FSH and LH levels (13.30 \& 11.92\%, respectively), compared to the low dose PENZ-treated rats. In addition, supplementation of SSO prior to the high dose PENZ intox- ication significantly suppressed serum estradiol level (8.09\%) and increased serum FSH and LH levels (18.17 \& 21.10\%), compared to the high dose PENZ-treated rats (Table 3).

Table 3: Effect of treatment with sesame seed oil (SSO) and/or penconazole (PENZ) on the level of serum testosterone (T), estradiol (E2), follicle stimulating hormone (FSH) and luteinizing hormone (LH) in male rats.

\begin{tabular}{|c|c|c|c|c|}
\hline \multirow{2}{*}{ Groups } & $\mathbf{T}$ & $\mathbf{E}_{2}$ & FSH & LH \\
\hline & (ng/ml) & $(\mathrm{pg} / \mathrm{ml})$ & (ng/ml) & (ng/ml) \\
\hline \multicolumn{5}{|l|}{ Normal Control } \\
\hline Mean \pm SD & $2.88 \pm 0.43$ & $16.46 \pm 1.86$ & $14.34 \pm 0.41$ & $40.56 \pm 1.21$ \\
\hline \multicolumn{5}{|c|}{ Negative Control (SSO) } \\
\hline Mean \pm SD & $3.05 \pm 0.10^{\mathrm{d}}$ & $17.86 \pm 0.42^{\text {cdef }}$ & $14.90 \pm 0.82^{\text {cdef }}$ & $42.04 \pm 2.17^{\text {cdef }}$ \\
\hline${ }^{*}$ Change $\%$ & 5.9 & 8.51 & 3.91 & 3.65 \\
\hline \multicolumn{5}{|c|}{ Positive Control I (LD PENZ) } \\
\hline Mean \pm SD & $2.95 \pm 0.42^{\mathrm{d}}$ & $24.81 \pm 1.59^{\text {abdef }}$ & $11.43 \pm 0.77^{\text {abdef }}$ & $33.46 \pm 1.56^{\text {abde }}$ \\
\hline${ }^{*}$ Change $\%$ & 2.43 & 50.73 & -20.29 & -17.5 \\
\hline \multicolumn{5}{|c|}{ Positive Control II (HD PENZ) } \\
\hline Mean \pm SD & $5.67 \pm 0.19^{\text {abce }}$ & $21.99 \pm 0.65^{\text {abcf }}$ & $8.86 \pm 0.33^{\text {abcef }}$ & $27.11 \pm 0.84^{\text {abcef }}$ \\
\hline${ }^{*}$ Change $\%$ & 96.88 & 33.6 & -38.21 & -33.16 \\
\hline \multicolumn{5}{|c|}{ Preventive I (SSO+LD PENZ) } \\
\hline Mean \pm SD & $2.95 \pm 0.12^{\mathrm{d}}$ & $22.87 \pm 1.26^{\mathrm{abcf}}$ & $12.95 \pm 0.29^{\mathrm{abcdf}}$ & $37.45 \pm 0.53^{\mathrm{abcdf}}$ \\
\hline${ }^{*}$ Change $\%$ & 2.43 & 38.94 & -9.69 & -7.67 \\
\hline${ }^{* *}$ Change $\%$ & 0 & -7.82 & 13.3 & 11.92 \\
\hline \multicolumn{5}{|c|}{ Preventive II (SSO+HD PENZ) } \\
\hline Mean \pm SD & $2.97 \pm 0.76^{\mathrm{d}}$ & $20.21 \pm 0.54^{\text {abcde }}$ & $10.47 \pm 0.27^{\text {abcde }}$ & $32.83 \pm 0.93^{\text {abde }}$ \\
\hline${ }^{*}$ Change $\%$ & 3.13 & 22.78 & -26.99 & -19.06 \\
\hline ***Change\% $\%$ & -47.62 & -8.09 & 18.17 & 21.1 \\
\hline F-ratio & 36.5 & 35 & 96.15 & 88.19 \\
\hline
\end{tabular}

Note: Results are mean \pm standard deviation (SD). The F-ratio is significant at $p<0.05$. The letters $a, b, c, d, e$, and $f$ denote significant change versus the normal control group, SSO, LD PENZ, HD PENZ, SSO+LD PENZ, and SSO+HD PENZ groups, respectively. * ** , *** percentage change versus normal control, LD PENZ and HD PENZ groups, respectively.

Effect of treatment with SSO and/or PENZ on Serum Triiodothyronine (T3) and Thyroxine (T4) Levels

A significant decrease was recorded in serum T3 and T4 levels in low and high PENZ treated rats (11.76, 26.05, 13.61 \& $44.38 \%$, respectively), compared to the normal control group. Administration of SSO prior to the intoxication of rats with the low and high PENZ doses normalized serum T3 and T4 levels in the lower dose only. Intergroup comparison between PENZ-intoxicated rats and those administered SSO showed that SSO supplementation significantly ameliorated the level of serum T3 and T4 (11.43 \& $13.70 \%$, respectively), versus the low dose PENZ-treated rats. Similarly, a significant increase was recorded in serum T4 level following treatment of high PENZ-intoxicated rats with SSO, compared to high dose PENZ-intoxicated rats (Table 4). 
Table 4: Effect of treatment with sesame seed oil (SSO) and/or penconazole (PENZ) on the level of serum triiodothyronine (T3) and thyroxine (T4) in male rats.

\begin{tabular}{|c|c|c|}
\hline \multirow{2}{*}{ Groups } & $\mathrm{T}_{3}$ & $\mathrm{~T}_{4}$ \\
\hline & (ng/ml) & $(\mathrm{pg} / \mathrm{ml})$ \\
\hline \multicolumn{3}{|l|}{ Normal Control } \\
\hline Mean \pm SD & $1.19 \pm 0.07$ & $33.80 \pm 2.59$ \\
\hline \multicolumn{3}{|c|}{ Negative Control (SSO) } \\
\hline Mean $\pm S D$ & $1.22 \pm 0.02^{\mathrm{cdf}}$ & $34.60 \pm 0.89^{\mathrm{cdf}}$ \\
\hline${ }^{*}$ Change $\%$ & 2.52 & 2.37 \\
\hline \multicolumn{3}{|c|}{ Positive Control I (LD PENZ) } \\
\hline Mean $\pm S D$ & $1.05 \pm 0.01^{\text {abdef }}$ & $29.20 \pm 1.48^{\text {abde }}$ \\
\hline *Change\% & -11.76 & -13.61 \\
\hline \multicolumn{3}{|c|}{ Positive Control II (HD PENZ) } \\
\hline Mean \pm SD & $0.88 \pm 0.04^{\text {abce }}$ & $18.80 \pm 4.97^{\text {abcef }}$ \\
\hline${ }^{*}$ Change $\%$ & -26.05 & -44.38 \\
\hline \multicolumn{3}{|c|}{ Preventive (SSO+LD PENZ) } \\
\hline Mean \pm SD & $1.17 \pm 0.05^{\mathrm{cdf}}$ & $33.20 \pm 2.28^{\mathrm{cdf}}$ \\
\hline${ }^{*}$ Change $\%$ & -1.68 & -1.78 \\
\hline${ }^{* *}$ Change $\%$ & 11.43 & 13.7 \\
\hline \multicolumn{3}{|c|}{ Preventive II (SSO+HD PENZ) } \\
\hline Mean \pm SD & $0.92 \pm 0.05^{\text {abce }}$ & $25.60 \pm 3.58^{\text {abde }}$ \\
\hline${ }^{*}$ Change $\%$ & -22.69 & -24.26 \\
\hline$* * *$ Change $\%$ & 4.55 & 36.17 \\
\hline F-ratio & 52.6 & 21.46 \\
\hline
\end{tabular}

Note: Results are mean \pm standard deviation (SD). The F-ratio is significant at $p<0.05$. The letters $a, b, c, d, e$, and $f$ denote significant change versus the normal control group, SSO, LD PENZ, HD PENZ, SSO+LD PENZ, and SSO+HD PENZ groups, respectively. * **, *** percentage change versus normal control, LD PENZ and HD PENZ groups, respectively.

Effect of Treatment with SSO and/or PENZ on Testicular Vitamins (A, C and E)

The intoxication of male rats with low and high PENZ doses depleted the testicular endogenous antioxidant status, as manifested by the significant reduction in vitamin A \& E levels (26.47, 32.35 \& 37.12, 45.76\%, respectively) in both groups, as well as vitamin C concentration (15.16\%) in the high dose PENZtreated rats, compared to the normal control group. On the other hand, administration of SSO to PENZ-intoxicated rats normalized testicular vitamin A \& C levels in the low dose group, as well as vitamin A level in the high dose group. Intergroup comparison revealed that administration of SSO to low dose PENZ-treated rats significantly increased testicular vitamin C and E levels 1 14.74\% \& $75.47 \%$, respectively), compared to the low dose PENZ-treated rats. In addition, administration of SSO to the high dose PENZ-treated rats produced a significant rise in testicular vitamin $A$ and $E$ levels (43.48 \& 40.63\%, respectively), compared to the high dose PENZtreated rats (Table 5). 
Table 5: Effect of treatment with sesame seed oil (SSO) and/or penconazole (PENZ) on testicular vitamins (A, C and E).

\begin{tabular}{|c|c|c|c|}
\hline \multirow{2}{*}{ Groups } & Vit A & Vit C & Vit E \\
\hline & ( $\mu \mathrm{g} / \mathrm{g}$ tissue $)$ & (mg/g tissue) & ( $\mu \mathrm{g} / \mathrm{g}$ tissue) \\
\hline Normal Contrc & \multirow[b]{2}{*}{$0.34 \pm 0.05$} & \multirow[b]{2}{*}{$3.43 \pm 0.55$} & \multirow[b]{2}{*}{$11.80 \pm 1.31$} \\
\hline Mean \pm SD & & & \\
\hline \multicolumn{4}{|c|}{ Negative Control (SSO) } \\
\hline Mean \pm SD & $0.30 \pm 0.05^{\mathrm{d}}$ & $3.20 \pm 0.25^{\mathrm{e}}$ & $11.25 \pm 0.71^{\text {cdef }}$ \\
\hline${ }^{*}$ Change $\%$ & -11.76 & -6.71 & -4.66 \\
\hline \multicolumn{4}{|c|}{ Positive Control I (LD PENZ) } \\
\hline Mean \pm SD & $0.25 \pm 0.03^{\mathrm{af}}$ & $3.12 \pm 0.13^{\mathrm{e}}$ & $7.42 \pm 1.13^{\text {abef }}$ \\
\hline${ }^{*}$ Change $\%$ & -26.47 & -9.04 & -37.12 \\
\hline \multicolumn{4}{|c|}{ Positive Control II (HD PENZ) } \\
\hline Mean $\pm S D$ & $0.23 \pm 0.01^{\text {abef }}$ & $2.91 \pm 0.09^{\mathrm{ae}}$ & $6.40 \pm 0.48^{\text {abef }}$ \\
\hline${ }^{*}$ Change $\%$ & -32.35 & -15.16 & -45.76 \\
\hline \multicolumn{4}{|c|}{ Preventive I (SSO+LD PENZ) } \\
\hline Mean \pm SD & $0.30 \pm 0.03^{\mathrm{d}}$ & $3.58 \pm 0.12^{\mathrm{bcdf}}$ & $13.02 \pm 0.33^{\text {abcdf }}$ \\
\hline${ }^{*}$ Change $\%$ & -11.76 & 4.37 & 10.34 \\
\hline${ }^{* *}$ Change $\%$ & 20 & 14.74 & 75.47 \\
\hline \multicolumn{4}{|c|}{ Preventive II (SSO+HD PENZ) } \\
\hline Mean \pm SD & $0.33 \pm 0.06^{\text {cd }}$ & $3.00 \pm 0.10^{\text {ae }}$ & $9.00 \pm 1.06^{\text {abcde }}$ \\
\hline${ }^{*}$ Change $\%$ & -2.94 & -12.54 & -23.73 \\
\hline${ }^{* * *}$ Change $\%$ & 43.48 & 3.09 & 40.63 \\
\hline F-ratio & 5.01 & 4.78 & 41.24 \\
\hline
\end{tabular}

Note: Results are mean \pm standard deviation (SD). The F-ratio is significant at $p<0.05$. The letters a, b, c, d, e, and f denote significant change versus the normal control group, SSO, LD PENZ, HD PENZ, SSO+LD PENZ, and SSO+HD PENZ groups, respectively. *, **, *** percentage change versus normal control, LD PENZ and HD PENZ groups, respectively.

Effect of Treatment with SSO and/or PENZ on Testicular Histology

A normal histological structure of the mature, active seminiferous tubules with complete spermatogenic series was noticed in the testes of normal rats and those supplemented with SSO (Figure 1A). Treatment of male rats with the low PENZ dose caused testicular degeneration in most of the seminiferous tubules along with increased intertubular space (Figure 1B). In addition, the high PENZ dose induced degeneration, atrophy and desquamation in the seminiferous tubules, as well as the absence of spermatogenic series, increased intertubular space and congestion in stromal blood vessels (Figure 1C). On the other hand, the administration of SSO prior to the low PENZ dose intoxication caused the irregular arrangement of spermatogenic series in some tubules and desquamation in seminiferous tubule (Figure 1D). By contrast, rats co-administered SSO with high PENZ dose intoxication demonstrated a normal intact histological structure of most of the seminiferous tubules, whereas maturation arrest was noticed in other seminiferous tubules (Figure 1E). 

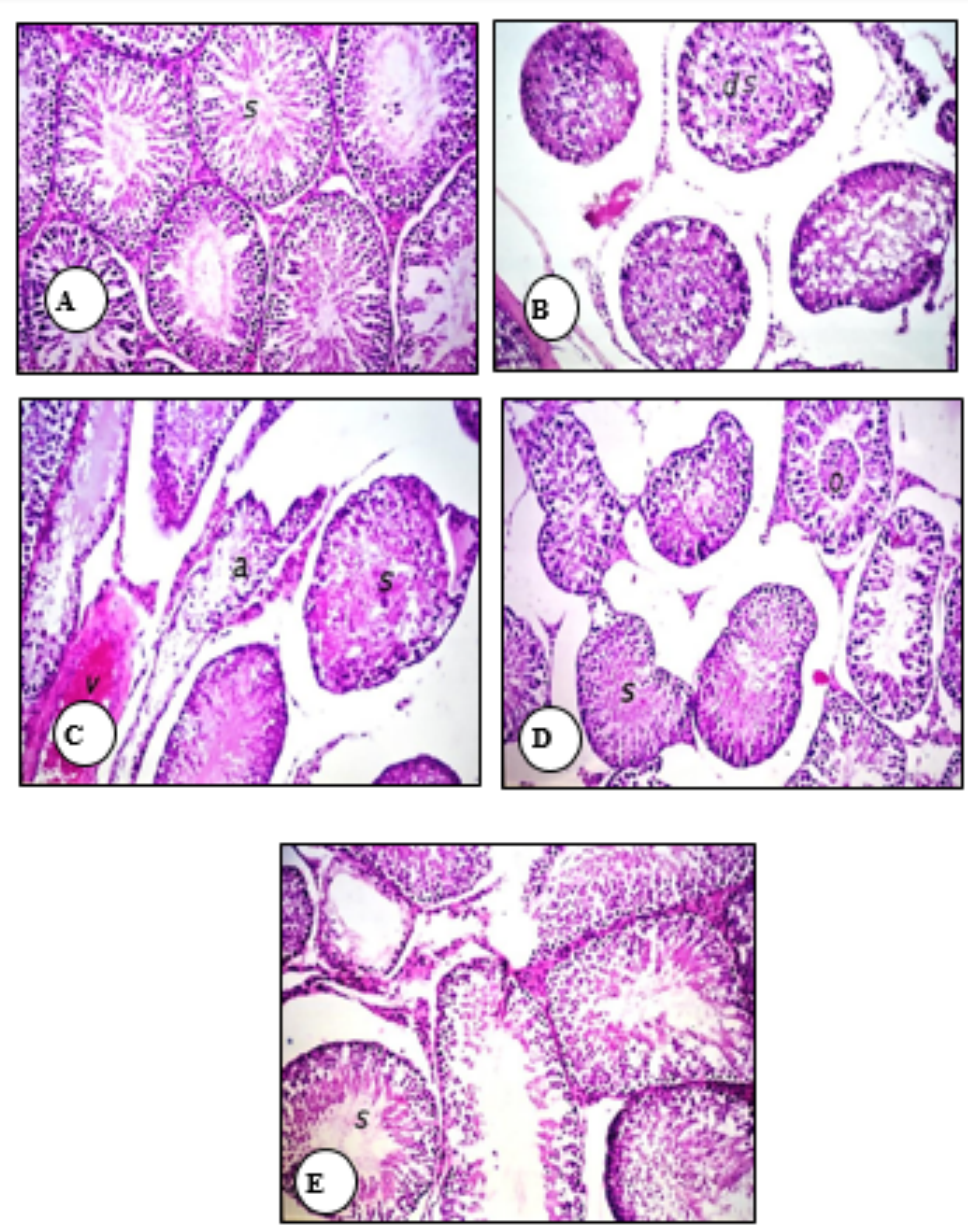

Figure 1: Photomicrographs of rat testis sections stained with haematoxylin and eosin (40). The normal histological structure of the mature, active seminiferous tubules with complete spermatogenic series (s) in normal control and SSO-treated animals was shown (A). The testis of a low dose PENZ-treated rat showed degeneration in most of the seminiferous tubules (ds) and increased intertubular space (B). The high dose PENZ-treated rat demonstrated increased testicular intertubular space, degenerated (s) and atrophied (a) seminiferous tubules, absence of spermatogenic series, congestion in stromal blood vessels, hemorrhage (v) inside the seminiferous tubules as well as desquamation (C). The testis of a male rat administered SSO before the low dose PENZ intoxication showed the irregular arrangement of spermatogenic series in some tubules (s) and desquamation (o) in seminiferous tubules (D). A male rat administered SSO before the high dose PENZ intoxication demonstrated almost a normal intact histological structure of most of the seminiferous tubules (s) and maturation arrest in other seminiferous tubules (E).

\section{Discussion}

Many chemicals, including pesticides with their widespread presence in the environment, have been suspected over recent decades to be endocrine disruptors [28]. Also, there is much concern that exposure to pesticides may cause reproductive toxicity through impairment of sperm motility, decreasing sperm counts, reducing fertilization ability and producing abnormal sperms [29]. Reproductive toxicity of PENZ and other triazole fungicides had been previously reported $[1,16,30]$. Therefore, abnormalities in sperm morphology in the current result could be attributed to a direct action of PENZ on testicular compartments, or due to an indirect manifestation through altered epididymal functions. The reduction in fertility indices in PENZ-treated rats may be due to impaired spermatogenic activity in the testes and maturation process in the epididymis. Uzunhisarcikli et al. [31] rseported that disruption of spermatogenesis and the increase in abnormal sperm count are important markers of genetic damage in pesticideexposed mammals. In addition, physiological concentrations of testosterone, LH and FSH play an important role in spermatogenesis and any disturbance in this homeostasis reduces the number and function of somatic and germinal cells of the testes [32].

Penconazole probably blocked gonadotropin synthesis and/or release by the pituitary, bound with the FSH receptor on Sertoli cells and prevent the production and release of androgen binding protein or exerted a negative feedback inhibition on the hypothalamuspituitary-gonadal (HPG) axis that subsequently reduced serum LH and FSH levels, causing spermatogenesis arrest. Histopathological examinations of the testes of PENZ-treated rats in the present study 
showed degeneration and atrophy in the seminiferous tubules and low luminal spermatozoa concentration. It is therefore reasonable to suggest that the decrease in the sperm count is an ultimate outcome of spermatogenic arrest following PENZ intoxication. Also, abnormalities in sperm morphology could be attributed to a direct toxic injury of PENZ, at both doses, to seminiferous tubules.It is well known that antioxidants enhance fertility, since antioxidant-rich plants improve sperm morphology and increase sperm motility and counts [33]. Therefore, the observed ameliorative effect of SSO on the fertility indices of PENZ-treated rats could be attributed to its high contents from free radical scavenger antioxidants [34].

In agreement with our finding, Ukwenya et al. [35] studied the effect of the alcoholic extract of sesame seed on the fertility of male Sprague Dawley rats and recorded an elevation in sperm motility. Thyroid hormones are essential for normal spermatogenesis and regulate testicular function in rats of all ages [36]. Thus far, the literature contains no evidence regarding the effect of PENZ on thyroid hormones. We reported a dose-dependent decrease in the level of serum T3 and T4 following intoxication of male rats with PENZ. A direct toxic effect of PENZ on the thyroid gland was histologically confirmed in the current study (data not shown). It has been reported that pesticides, including triazoles, can devastate the reproductive system by changing the hormonal balance [37]. Accordingly, the disturbance in serum androgen-estrogen balance and fertility hormones level in the present study is a clear evidence for the endocrine disrupting potential of PENZ. Generally, triazoles increase serum testosterone level and lead to hepatomegaly and fertility reduction $[38,39]$.

Triazoles had been reported to disrupt testosterone homeostasis in rats via downregulating the expression of hepatic genes involved in testosterone metabolism, along with upregulating testicular expression of genes involved in testosterone synthesis [40]. As compared to the respective positive control groups, the slight significant reduction in serum estradiol level of PENZ-intoxicated SSO-supplemented rats can be attributed to a probable inhibition of aromatase enzyme by sesame oil lignans or the reduced usage of endogenous estradiol. In addition, SSO probably counterbalanced PENZ-induced disruption of testosterone homeostasis either directly by protecting the testis or indirectly by increasing the expression of testosterone-metabolizing enzymes. Furthermore, the significant decrease in serum estradiol and testosterone levels might contribute to the reduction in the feedback inhibition of $\mathrm{LH}$ and FSH secretions. Several probable mechanisms might contribute to the enhancement of thyroid hormones in SSO-supplemented PENZ-intoxicated rats, which include a direct protective effect against PENZ-induced thyrotoxicosis through the potent antioxidant potential of SSO components that preserved thyroid structures (data not shown).

Wolf et al. [41] administered triadimefon (1800 ppm), propiconazole (2500 ppm) and myclobutanil (2000 ppm), all are triazole fungicides, in the food of adult male Wistar/Han rats for one and three months. The authors reported a significant increase in hepatic microsomal uridine diphospho-glucuronyl transferase (UDPGT) activity for all three conazoles, which accounts for the general decrease in circulating T3 and T4 levels. Consequently, we assume that SSO counterbalanced the tendency of penconazole (as a triazole) to induce the activity of UDGPTs, minimizing thyroid hormones metabolism, preserving therefore their systemic levels. We previously demonstrated that PENZ induced oxidative damage in the testis of adult male rats, as evidenced by the enhancement of lipid peroxidation and suppression of antioxidant enzymes (catalase and superoxide dismutase), and that administration of SSO prior to PENZ intoxication protected the testes from the induced oxidative stress by lowering the testicular lipid peroxidation level and inducing antioxidant enzymes activity [42]. Antioxidant vitamins, including A, C and E, were reported to reduce chlorpyrifos-induced lipid peroxidation in different organs, by inhibiting the DNA damage induced by reactive oxygen metabolites, preventing therefore ultimate genetic changes [43].

Vitamin C is present in the spermatogenic chamber and Leydig cells and protects spermatogenesis, increases testosterone levels, prevents sperm agglutination and plays a major role in semen integrity and fertility [44]. Also, vitamins A and E act as antioxidants and stabilize testicular cell membranes by reducing lipid peroxidation [45]. The depletion of the aforementioned vitamins in the testis of PENZ-treated rats resulted from their utilization in antioxidant reactions with radicals generated by PENZ. By contrast, administration of SSO prior to PENZ intoxication normalized testicular vitamin A level and significantly increased vitamin $\mathrm{C}$ and $\mathrm{E}$ levels, compared to PENZ-treated rats. Sesame seed oil is well known for its oxidative stability, which is attributed to its vitamin $\mathrm{C}$ and tocopherol contents. Hemalatha \& Ghafoorunissa [46]reported that sesame lignans increase tissue tocopherol levels by inhibition of CYP450 3A- dependent n-hydroxylase pathways of tocopherol catabolism, enhancing therefore the quality and morphology of the produced sperms, which ultimately protected the testis from PENZ-induced damage in the current study. Therefore, SSO supplementation decreased the generation of ROS, prevented PENZ-induced derangements in the antioxidant system and improved the redox status in testicular tissues.

\section{Conclusion}

The current study demonstrated an endocrine disrupting potential and a testicular toxicity for PENZ in adult male rats. Oral administration of SSO was effective in minimizing the endocrine disruption and counterbalancing the toxic effects of PENZ on the male reproductive system. It is important to consider the possibility of SSO as a food supplement for men in agriculture practice to minimize the toxic effects on male fertility and to limit the toxicity against pesticides-exposure on the reproductive system. 


\section{Acknowledgment}

The authors would like to acknowledge the technical assistance in histopathological examination and the valuable comments of Prof. Dr Adel Bakeer (Faculty of Veterinary Medicine, Cairo University, Egypt).

\section{References}

1. El-Sharkawy EE, El-Nisr NA (2013) Testicular dysfunction induced by penconazole fungicide on male albino rats. Comparative Clinical Pathology 22: 475-480.

2. Zarn JA, Brüschweiler BJ, Schlatter JR (2003) Azole fungicides affect mammalian steroidogenesis by inhibiting sterol 14 alpha-demethylase and aromatase. Environ Health Perspect 111(3): 255-261.

3. Chaâbane M, Soudani N, Benjeddou K, Turki M, Makni FA, et al. (2015) The protective potential of Nitraria retusa on penconazole-induced hepatic injury in adult rats. Toxicology and Environmental Chemistry 97: 1-12.

4. Chaâbane M, Tir M, Hamdi S, Boudawara O, Jamoussi K, et al. (2016) Improvement of heart redox states contributes to the beneficial effects of selenium against penconazole-induced cardiotoxicity in adult rats. Biological Trace Element Research 169: 261-270.

5. Chaâbane M, Ghorbel I, Elwej A, Mnif H, Boudawara T, Chaâbouni SE et al. (2017) Penconazole alters redox status, cholinergic function, and membrane-bound ATPases in the cerebrum and cerebellum of adult rats. Human and Experimental Toxicology 36: 854-866.

6. Choi AM, Lee SB, Cho SH, Hwang I, Hur CG, et al. (2008) Isolation and characterization of multiple abundant lipid transfer protein isoforms in developing sesame (Sesamum indicum) seeds Plant. Physiology and Biochemistry 46: 127-139.

7. Kanu PJ, Bahsoon JZ, Kanu JB, Kandeh JBA (2010) Nutraceutical importance of sesame seed and oil: A review of the contribution of their lignans Sierra Leone. J of Biomed Resh 2(1).

8. Nakano D, Itoh C, Ishii F, Kawanishi H, Takaoka M, et al. (2003) Effects of sesamin on aortic oxidative stress and endothelial dysfunction in deoxycorticosterone acetate-salt hypertensive rats. Biol Pharm Bull 26(12): 1701-1705.

9. Chen PR, Chien KL, Su TC, Chang CJ, Liu TL, et al. (2005) Dietary sesame reduces serum cholesterol and enhances antioxidant capacity in hypercholesterolemia. Nutrition Research 25: 559-567.

10. Jeng KC, Hou RC, Wang JC, Ping LI (2005) Sesamin inhibits lipopolysaccharide-induced cytokine production by suppression of p38 mitogen-activated protein kinase and nuclear factor-kappaB Immunol Lett 97(1): 101-106.

11. Tsuruoka N, Kidokoro A, Matsumoto I, Abe K, Kiso Y (2005) Modulating effect of sesamin, a functional lignan in sesame seeds, on the transcription levels of lipid- and alcohol-metabolizing enzymes in rat liver: a DNA microarray study. Biosci Biotechnol Biochem 69(1): 179-188.

12. Yokota T, Matsuzaki Y, Koyama M, Hitomi T, Kawanaka M, et al. (2007) Sesamin, a lignan of sesame, down-regulates cyclin D1 protein expression in human tumor cells. Cancer Sci 98(9): 1447-1453.

13. Chung BH, Lee JJ, Kim JD, Jeoung D, Lee H, et al. (2010) Angiogenic activity of sesamin through the activation of multiple signal pathways. Biochemical and Biophysical Research Communications 391: 254-260.

14. Khan MM, Ishrat T, Ahmad A, Hoda MN, Khan MB, et al. (2010) Sesamin attenuates behavioral, biochemical and histological alterations induced by reversible middle cerebral artery occlusion in the rats. Chem Biol Interact 183(1): 255-263.

15. Mathur N, Pandey G, Jain GC (2010) Pesticides: A review of the male reproductive toxicity J Herbal Med Toxicol 4: 1-8.
16. Aiche MA, Mallem L, Yahia E, Boulakoud MS (2015) Toxicity of subchronic doses of propiconazole, propineb and their mixture on reproductive parameters in male rats. Advances in Environmental Biology 9: 885-891.

17. National Research Council (US) Committee for the Update of the Guide (2011) Guide for the Care and Use of Laboratory Animals 8th ed, Washington (DC): National Academies Press

18. OECD Guideline for Testing of Chemicals (1987) Acute Oral Toxicity pp. 401.

19. Hsu DZ, Liu MY (2002) Sesame oil attenuates multiple organ failure and increases survival rate during endotoxemia in rats. Crit Care Med 30: 1859-1862.

20. Henry RJ, Cannon DC, Winkelman JW (eds) (1974) Clinical Chemistry: Principles and Technics Hagerstown, Harper and Row, pp. 1371-142

21. Hinds FC, Cmarik GF, Mansfield ME, Zimmerman JE (1968) Influence of aspiration biopsy of liver on cattle gains and liver vitamin A values. J Anim Sci 27(2): 505-550.

22. Pett LB, LePage G A (1940) Vitamin A deficiency III Blood analysis correlated with a visual test. J of Biol Chem 132: 585-593.

23. Martinek RG (1964) Method for the determination of vitamin E (total tocopherols) in serum. Clin Chem 10: 1075-1068.

24. Feuston MH, Bodnar KR, Kerstetter SL, Grink CP, Belcak MJ, et al. (1989) Reproductive toxicity of 2-methoxyethanol applied dermally to occluded and nonoccluded sites in male rats. Toxicol Appl Pharmacol 100(1): 145161.

25. Linder RE, Strader LF, McElroy WK (1986) Measurement of epididymal sperm motility as a test variable in the rat. Bulletin of Environmental Contamination Toxicol 36(3): 317-324.

26. Krzanowska H, Styrna J, Wabik Sliz B (1995) Analysis of sperm quality in recombinant inbred mouse strains: correlation of sperm head shape with sperm abnormalities and with the incidence of supplementary spermatozoa in the perivitelline space. J Reprod Fertil 104(2): 347-354.

27. Weil CS (1952) Tables for convenient calculation of median-effective dose (LD50 or ED50) and instructions in their use. Biometrics 8(3): 249-263.

28. Haraux E, Braun K, Buisson P, Stéphan-Blanchard E, Devauchelle C, et al (2017) Maternal exposure to domestic hair cosmetics and occupational endocrine disruptors is associated with a higher risk of hypospadias in the offspring. Int J Environ Res Pub Health, 14: 27.

29. Alm H, Tiemann U, Torner H (1996) Influence of organochlorine pesticides on development of mouse embryos in vitro. Reproductive Toxicology 10: 321-326.

30. Kumar PR, Kanniappan M, Mathuram LN, Selvasubramanian S, Manohar $\mathrm{BM}$, et al. (2011) Hexaconazole induced changes in the histological architecture of male and female reproductive systems in rats. Res J Pharmcol 5: 9-13.

31. Uzunhisarcikli M, Kalender Y, Dirican K, Kalender S, Ogutcu A, et al. (2007) Acute, subacute and subchronic administration of methyl parathion-induced testicular damage in male rats and protective role of vitamins C and E. Pesticide Biochem Physiol 87(2): 115-122.

32. Selim ME, Aleisa NA, Daghestani MH (2013) Evaluation of the possible protective role of quercetin on letrozole-induced testicular injury in male albino rats. Ultrastruct Pathol 37(3): 204-217.

33. Oluyemi KA, Jimoh OR, Adesanya OA, Omotuyi IO, Josiah SJ, et al. (2007) Effects of crude ethanolic extract of Garcinia cambogia on the reproductive system of male Wistar rats (Rattus Novergicus). African J of Biotechnol 6(10): 1236-1238.

34. Amini Mahabadi J, Khodayari M, Hassani Bafrani H, Nikzad H, Taherian A, et al. (2013) Effect of diet containing sesame seed on epididymal histology of adult rat. African Journal of Pharmacy and Pharmacology 7: 132-137. 
35. Ukwenya V, Oluyemi K, Ashamu E, Saalu C, Oyewo O, et al. (2007) Profertility effects of alcoholic extract of sesame in male SpragueDawley rats. J Nut Well, 5: 121-127.

36. Maran RR, Aruldhas MM (2002) Adverse effects of neonatal hypothyroidism on Wistar rat spermatogenesis. Endocr Res 28(3): 141154.

37. Abbassy MA, Marzouk MA, Nasr HM, Mansy ASM (2014) Effect of imidacloprid and tetraconazole on various hematological and biochemical parameters in male albino rats (Rattus Norvegicus). Polit Sci Pub Affa, 2: 122

38. Goetz AK, Ren H, Schmid JE, Blystone CR, Thillainadarajah I, et al. (2007) Disruption of testosterone homeostasis as a mode of action for the reproductive toxicity of triazole fungicides in the male rat Toxicol Sci 95(1): 227-239.

39. Hester S, Moore T, Padgett WT, Murphy L, Wood CE, et al. (2012) The hepatocarcinogenic conazoles: cyproconazole, epoxiconazole, and propiconazole induce a common set of toxicological and transcriptional responses. Toxicol Sci 127(1): 54-65.

40. Goetz AK, Dix DJ. (2009) Mode of action for reproductive and hepatic toxicity inferred from a genomic study of triazole antifungals. Toxicol Sc $110(2): 449-462$

ISSN: 2574-1241

DOI: 10.26717.BJSTR.2019.14.002486

Mahmoud M Said. Biomed J Sci \& Tech Res

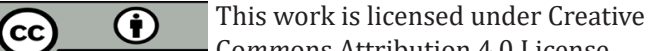
Commons Attribution 4.0 License

Submission Link: https://biomedres.us/submit-manuscript.php
41. Wolf DC, Allen JW, George MH, Hester SD, Sun G, et al. (2006) Toxicity profiles in rats treated with tumorigenic and nontumorigenic triazole conazole fungicides: propiconazole, triadimefon, and myclobutanil. Toxicol Pathol 34(7): 895-902.

42. Borai IH, Atef AA, El Kashoury, AA Said, MM Mohamed RA, et al. (2017) The protective role of sesame seed oil against penconazole-induced oxidative stress in the testes of male rats. Egyptian Journal of Agricultural Research 95: 1581-1595.

43. Verma RS, Meht A, Srivastava N (2007) In vivo chlorpyrifos induced oxidative stress: attenuation by antioxidant vitamins. Pesticide Biochemistry and Physiology 88(2): 191-196.

44. Sönmez M, Türk G, Yüce A (2005) The effect of ascorbic acid supplementation on sperm quality, lipid peroxidation and testosterone levels of male Wistar rats. Theriogenology 63: 2063-2072.

45. El-Kashoury A, Mansour MK (2007) Chronic exposure to organochlorine pesticide, dicofol, induced oxidative stress in testes of albino rats. Bulletin of Faculty of Pharmacy Cairo University 45: 245-252.

46. Hemalatha S, Ghafoorunissa (2004) Lignans and tocopherols in Indian sesame cultivars. J of the American Oil Chemists Society 81(5): 467-470.

\begin{tabular}{ll} 
BIOMEDICAL & Assets of Publishing with us \\
RESEARCHES & - Global archiving of articles \\
& - Immediate, unrestricted online access \\
\hline ISSN: 2574-1241 & - Rigorous Peer Review Process \\
\hline
\end{tabular}

